\title{
Sugar tax and screening: listen to the evidence
}

\author{
Fiona Godlee editor in chief
}

The BMJ

\begin{abstract}
"Sugar, rum, and tobacco are commodities which are nowhere necessaries of life, which are become objects of almost universal consumption, and which are therefore extremely proper subjects of taxation." So wrote Adam Smith in his 1776 Inquiry into the Nature and Causes of the Wealth of Nations. So what will today's UK government decide? Will its obesity strategy, due to be published later this month, include a sugar tax? Last year the prime minister, David Cameron, ruled this out. It would be nice to think that the latest, much anticipated evidence from Mexico, published this week in The BMJ, might lead him to reconsider.
\end{abstract}

Mexico imposed a tax on sugar sweetened drinks in 2014 as part of a wide ranging strategy to combat obesity. In the first evaluation of the early effects, $M$ A Colchero and colleagues report a higher than expected drop in consumption of sugary drinks after the tax was introduced, while consumption of untaxed drinks, mainly bottled water, rose (doi:10.1136/bmj. h6704). The changes were greatest in poorer households, and they accelerated over time.

In his commentary on the research, Franco Sassi, head of the public health programme at the Organisation for Economic Co-operation and Development, says that these results are not surprising but are of the greatest importance to governments around the world (doi:10.1136/bmj.h6904). Taxes should, of course, be part of a broader anti-obesity strategy, alongside regulation and health education. Taxes work, Sassi says, largely because they send a strong signal to consumers and manufacturers that a government is serious about tackling the harms of unhealthy diets. I just hope David Cameron's advisers are listening.

Elsewhere this week comes a clarion call for more honest communication of the benefits of screening for cancer. Most studies report only cancer specific mortality, allowing researchers and policy makers to claim that screening "saves lives.” Vinay Prasad and colleagues (doi:10.1136/bmj.h6080) remind us that disease specific mortality won't show deaths resulting from the screening procedures themselves or from subsequent tests and treatments. For this we need all cause mortality. In a linked editorial Gerd Gigerenzer adds a further request to researchers, to report overall cancer mortality (doi:10. 1136/bmj.h6967). For complete clarity, he recommends "fact boxes" displaying all three measures.

To know whether screening really saves lives we would need trials far larger than any that have yet been done. Our commentators aren't all convinced that these would be worth the cost. But they and I agree that failing to report the full picture misleads the public, for which there is no excuse. "The harms of screening are certain, but the benefits in overall mortality are not," Prasad and colleagues conclude. 